\title{
Nutritional Status of Indian Children with Cerebral Palsy: A Cross-sectional Study
}

\author{
Riya Goyal ${ }^{1} \cdot$ Radhamohan Rana $^{1} \cdot$ Hitesh Bhatia ${ }^{1}$ - Jaya Shankar Kaushik ${ }^{1}$ (B)
}

Received: 20 July 2019 / Accepted: 16 September 2019 / Published online: 7 November 2019

(C) Dr. K C Chaudhuri Foundation 2019

To the Editor: Nutritional problems are prevalent among children with chronic neurological illness, including cerebral palsy [1]. Children with cerebral palsy are prone to feeding problems owing to oropharyngeal dysphagia, oromandibular dystonia, and gastroesophageal reflux disease [2]. The present study aimed to describe the nutritional status and dietary intake of children with cerebral palsy (CP) aged six months to five years and to describe the demographic and clinical predictors of malnutrition among children with $\mathrm{CP}$.

A cross-sectional study was conducted among 50 children with CP or evolving CP. Their demographic profile, anthropometric assessment [including weight for height (WFH), height for age (HFA)], functional ability [GMFCS (Gross Motor Functional Classification System)] and dietary intake (24-h dietary recall method) were recorded. World Health Organization (WHO) classification for malnutrition was adopted based on WFH and HFA.

A total of 50 children [31(62\%) males] were enrolled; of whom severe malnutrition was present in 18 (36\%) with 12 $(24 \%)$ children having WFH $<3 \mathrm{SD}$ (severe wasting) and 12 $(24 \%)$ having HFA $<3$ SD (severe stunting) as per WHO classification. A mean (SD) calorie deficit of 425 (41.6) Kcal was observed. However, despite lack of statistical significance, children with comorbid epilepsy [OR-3.35 (0.59-19.02); $p=0.17$ ], GMFCS grade IV and V [OR-2.72 (0.36-20.66); $p=0.33$, and dyskinetic type of CP [OR-3.24 (0.53-19.76); $p=0.22]$ had higher odds of malnutrition. However, it was observed that none of the factors including the age of the patient, gender, GMFCS grading, type of cerebral palsy,

Presentation at a meeting: The paper was presented as poster presentation at Asian and Oceanian Congress of Child Neurology, Malaysia, $19^{\text {th }}$ to $22^{\text {nd }}$ Sept 2019.

Jaya Shankar Kaushik

jayashankarkaushik@gmail.com

1 Department of Pediatrics, Pt B D Sharma Post Graduate Institute of Medical Sciences, Rohtak, Haryana 124001, India presence of comorbid epilepsy and calorie deficit were significant independent predictors of severe malnutrition.

The present study with limited sample size and crosssectional study design revealed a $36 \%$ prevalence of malnutrition among children with cerebral palsy. Prevalence of malnutrition varies widely based on the definition and criteria adopted to define malnutrition. Prevalence of malnutrition ranges from 25 to $95 \%$ among children with cerebral palsy [3-5]. In the present study, we observed that children with higher GMFCS, dyskinetic type of CP and those with comorbid epilepsy had higher odds of malnutrition. Considering one-third of children affected with malnutrition, we believe all children with $\mathrm{CP}$ must be screened for malnutrition. Nutritional rehabilitation must be an essential, integral aspect of management of children with cerebral palsy.

\section{Compliance with Ethical Standards}

Conflict of Interest None.

\section{References}

1. Sankar C, Mundkur N. Cerebral palsy-definition, classification, etiology and early diagnosis. Indian J Pediatr. 2005;72:865-8.

2. Benfer KA, Weir KA, Bell KL, Ware RS, Davies PSW, Boyd RN. Oropharyngeal dysphagia and cerebral palsy. Pediatrics. 2017;140: e20170731.

3. Singhi PD, Ray M, Suri G. Clinical spectrum of cerebral palsy in north India-an analysis of 1,000 cases. J Trop Pediatr. 2002;48:1626.

4. Aydin K; Turkish Cerebral Palsy Study Group. A multicenter cross sectional study to evaluate the clinical characteristics and nutritional status of children with cerebral palsy. Clin Nutr ESPEN. 2018;26: $27-34$.

5. Kakooza-Mwesige A, Tumwine JK, Eliasson A-C, Namusoke HK, Forssberg H. Malnutrition is common in Ugandan children with cerebral palsy, particularly those over the age of five and those who had neonatal complications. Acta Paediatr. 2015;104:1259-68.

Publisher's Note Springer Nature remains neutral with regard to jurisdictional claims in published maps and institutional affiliations. 